\title{
Assessing a Tool for Self-Monitoring Hydration Using Urine Color in Pregnant and Breastfeeding Women: A Cross-Sectional, Online Survey
}

\author{
Marion Rigaud ${ }^{a}$ Camila Sevalho Corçao $^{a} \quad$ Erica T. Perrier ${ }^{a}$ \\ Sabine Boesen-Mariani ${ }^{b}$ \\ ${ }^{a}$ Danone Research, Palaiseau, France; ${ }^{b}$ Danone Nutricia Research, Utrecht, The Netherlands
}

\section{Keywords}

Urine color · Hydration · Self-assessment · Pregnancy .

Breastfeeding · Fluid intake

\begin{abstract}
Background: Pregnant and breastfeeding women experience great changes in their total body water content and water dynamics. To support the accretion of total body water during pregnancy and compensate for the water lost through breast milk during breastfeeding, increased adequate intakes (Al) for total water have been established by various health authorities. Despite this widespread advice, several studies suggest that pregnant and breastfeeding women do not meet the Al for total water, suggesting the need to raise women's awareness on the importance of adequate water intake, particularly during pregnancy and breastfeeding, as well as to provide them with a simple means of monitoring their hydration on a day-to-day basis. A urine color (UC) scale recently has been validated for hydration monitoring in pregnant and breastfeeding women. Summary: We sought to develop a version of a tool based on the UC scale, using only images or illustrations, which could be understood by users of various nationalities and spoken languages. Pregnant and breastfeeding women $(n=$
\end{abstract}

\begin{tabular}{ll}
\hline KARGER & $\begin{array}{l}\text { ( ) 2017 The Author(s) } \\
\text { Published by S. Karger AG, Basel }\end{array}$ \\
$\begin{array}{l}\text { E-Mail karger@karger.com } \\
\text { www.karger.com/anm }\end{array}$ & $\begin{array}{l}\text { This article is licensed under the Creative Commons Attribution- } \\
\text { NonCommercial-NoDerivatives 4.0 International License (CC BY- } \\
\text { NC-ND) (http://www.karger.com/Services/OpenAccessLicense). } \\
\text { Usage and distribution for commercial purposes as well as any dis- } \\
\text { tribution of mons }\end{array}$
\end{tabular}

1,275) from Brazil, Mexico, and Poland were shown 3 versions of the tool. Understanding, appreciation, simplicity and intent to use were evaluated using a questionnaire consisting of 26 items. Key Messages: Among the 3 versions tested, one tool emerged as the most highly understood (88\% spontaneous understanding) and was highly appreciated by users (mean [SD]: 8.40 [2.20] out of 10). There were no differences between countries. Furthermore, $83 \%$ reported being very likely to use the tool daily. These results suggest that a simple tool based on the UC scale will help pregnant and breastfeeding women meet the Al for total water.

(c) 2017 The Author(s)

Published by S. Karger AG, Basel

\section{Background}

During pregnancy, women experience great physiological changes, including a $20 \%$ increase of total water (i.e., approximately $7 \mathrm{~L}$ ), which is a substantial contributor to the average gestational weight gain of $12 \mathrm{~kg}$ at term [1]. Among other functions, this increased body water maintains amniotic fluid volume, facilitates plasma volume expansion, and represents a major part of the developing fetus. During lactation, the production of breast 
milk (which consists of $87 \%$ water) progressively increases, such that 6 weeks postpartum, it reaches an average of $750 \mathrm{~mL} \cdot \mathrm{day}^{-1}$, a significant, additional water loss $[2,3]$.

To support the accretion of total body water during pregnancy and compensate for the extra water lost through breast milk during breastfeeding, several health regulatory bodies worldwide have established increased adequate intakes (AI) for total water (originating from both fluids and food) for pregnant and breastfeeding women compared with non-pregnant, non-breastfeeding women. Both European [2] and North American [1] organizations propose an additional water consumption of $300 \mathrm{~mL} \cdot$ day $^{-1}$ during pregnancy, and then recommend an additional water intake of $700 \mathrm{~mL} \cdot \mathrm{day}^{-1}$ [2] or 1,100 $\mathrm{mL} \cdot$ day $^{-1}[1]$ during breastfeeding.

Despite this widespread advice to increase water intake during pregnancy and breastfeeding, few studies have investigated the water consumption patterns of pregnant and breastfeeding women around the world, and to what extent they meet AI during this period. In one study conducted with 308 pregnant or breastfeeding women in Mexico, $41 \%$ of pregnant women and $54 \%$ of breastfeeding women failed to meet national intake guidelines [4]. An Indonesian survey reported nearly identical results among 595 pregnant or breastfeeding women: $42 \%$ of pregnant women and $54 \%$ of breastfeeding women consumed less than the AI of water from fluids, established by the Indonesian Ministry of Health [5]. Finally, a recent observational study that followed a sample of American women, from the first trimester of pregnancy into early breastfeeding, reported mean total fluid intake levels of 2.3 and $2.1 \mathrm{~L} \cdot$ day $^{-1}$, respectively, which indicated that the women did not increase their water intake at all during the early weeks of breastfeeding [6].

These studies investigate fluid consumption in few countries, yet the findings consistently suggest the need to raise awareness of the importance of adequate water intake (AWI through water originating from fluids), particularly during pregnancy and breastfeeding, as well as to provide women with a simple means of monitoring their hydration levels on a day-to-day basis.

Urine output and more specifically urine concentration respond to changes in daily fluid intake [7]. Among measures of urine concentration, urine color (UC) is well suited for field use, as it can be measured without the use of special equipment, using a simple hand-held scale. An 8-point UC scale developed by Armstrong et al. $[8,9]$ has been shown to track day-to-day changes of hydration in healthy adults and in children [7, 10-13]. More recently, the validity of this tool to assess hydration in pregnant and breastfeeding women has also been established [14]. Moreover, in children, the use of the UC scale has been shown to improve hydration status in young athletes [15], suggesting that awareness plays a role in improving drinking behaviors. Given that many pregnant and breastfeeding women appear to fall short of AWI $[4,16]$, developing a tool based on the UC scale, specifically designed for this population, may encourage increased water consumption.

Because insufficient intake appears to be a global issue, we sought to develop a tool based on the UC scale, using only images or illustrations, which could be understood by users of various nationalities and spoken languages. Using a two-phase approach, we first worked with groups of pregnant and breastfeeding women and healthcare professionals (e.g., gynecologists, nutritionists, dietitians, midwives) to design 3 visuals that represented an illustrated hydration self-assessment tool based on the UC scale. Using these 3 visual versions of the UC scale, our aims were to (1) evaluate understanding, relevance for daily use, and appreciation of the tool among pregnant and breastfeeding women; and (2) select the most effective version of a tool based on the UC scale.

\section{Methods}

Description of the 3 Tools Based on the UC Scale

Three different visual representations of the 8-point UC scale developed by Armstrong et al. [8, 9] were created. In these 3 designs, the 8-point UC scale was divided into 3 sections (lightest 3 shades - you are doing well, middle 3 shades - pay attention, and darkest 2 shades - warning). Using the universal color code based on a traffic light, these groupings were delimited by colorcoded borders: green (lightest UC), orange (medium UC), and red (darkest UC). The first design, Tool 1, contained the following visual elements: the target population illustrated inside a water drop; and 3-step instructions for using the tool (drink; use the toilet; assess color). The 3 sections of the UC scale were supported by corresponding "smiley" faces indicating the evaluation of UC (smile, neutral expression, and frown, respectively, from lightest to darkest colors). Tool 2 followed a similar principle, with the sections of the UC scale associated with respective smiley faces in support. However, in Tool 2, there were 2 key differences: first, to the left of the UC scale, an illustration of a woman drinking more or less water was associated with each section of the scale. The aim was to link a woman's prior intake (high, moderate, low) to the color of urine. Second, the usage instructions in Tool 2 featured only 2 steps (water jug; UC). Tool 3 also included a representation of drinking water, but the positioning and intended message were different: instead of a link to (prior) water intake, each section of the UC scale was linked on the right
Rigaud/Sevalho Corçao/Perrier/ Boesen-Mariani 
side to an illustrated recommendation about what to do following the UC evaluation, namely, to increase water intake when UC is dark.

\section{Participants}

This study included 1,275 pregnant and breastfeeding women in Brazil, Mexico, and Poland. We defined quotas for the number of pregnant and breastfeeding women and also regarding women's status (primipara, or multipara), as first-time mothers-to-be may differ from more experienced mothers in their knowledge and awareness of hydration. Participants were recruited from an online access panel by a research agency (MetrixLab; Levallois-Perret, France). They received an email inviting them to take part in the study; those who expressed interest in participating received further written information. All participants read this information and had to attest that they read, understood, and agreed with the study content before they could begin the questionnaire.

\section{Data Collection}

The data were collected between November 4th and 18th, 2015, using an anonymous, self-completed, online questionnaire; the average completion time was 21 minutes. The questionnaire was first developed in English and translated by the research agency into the Portuguese, Spanish, and Polish languages. The translation and coherence with the English version were then assessed by native speakers from each of the 3 countries. In terms of content, the questionnaire consisted of 26 items including both open-ended questions, as well as 5-point and 10-point Likert-scales. Possible responses ranged from strong agreement, to neutral, to strong disagreement (Table 1). The questionnaire aimed to evaluate understanding, relevance of daily use, and appreciation of a tool based on the UC scale; it also aimed to assess baseline hydration awareness among the participants.

In order to evaluate the 3 design options of the tool, we sought to evaluate both spontaneous as well as guided understanding. First, to evaluate spontaneous understanding, participants were shown one of the 3 visuals, at random, without any explanation, and then asked in an open question, "What do you understand?". Participants then expressed how well they liked the design and answered true/false statements to assess their understanding in more depth. Next, following a short explanation of the tool, the participants responded to questions related to the perceived simplicity and relevance of the design shown. Finally, participants viewed the 3 tools, indicated their preference, and explained their preference in an open question.

\section{Statistical Analysis}

All data were analyzed using JMP 10 and SAS 9.2 statistical software. Items assessing positive or negative impressions with a 5 -point Likert-scale were grouped into "top 2" (strong agreement/agreement), neutral, and "bottom 2" (disagreement/strong disagreement) responses, and expressed as percentages. Appreciation, assessed with a 10 point scale, was converted into a continuous score and expressed as a mean (standard deviation). A Wilcoxon test was used to compare the mean appreciation between tools. The comparison of mean appreciation before and after explanation of each tool was done using a Wilcoxon rankedsigned test. To most open-ended items, participants provided free text responses, which ranged from a few words to several paragraphs. Two researchers read each of these responses mul-

Self-Monitoring Hydration Using UC in

Pregnant and Breastfeeding Women tiple times and developed an index of codes and themes across questions. Then, each researcher independently coded openended responses. A check for consistency between the 2 researchers revealed minimal differences, which were resolved through discussion. For the open question measuring spontaneous understanding ("What do you understand?"), researchers coded the answers into 4 categories:

(1) Understand totally: the tool was understood and both "UC" and "hydration" or "drinking water" were quoted.

(2) Partially understood: tool was partially understood and participant mentioned "UC" or "hydration" or "drinking water."

(3) Misunderstanding: participants listed ideas other than "UC" or "hydration."

(4) Don't know: participants stated not having understood anything.

Pearson chi-square tests were used to further analyze data regarding understanding (test of independence) and preference (test of goodness of fit) [17].

\section{Results}

\section{Respondent Characteristics}

The mean (SD) age of our sample was 28.6 (5.8) years. Respondents included $57 \%$ of pregnant women and $43 \%$ of breastfeeding women (Table 2). Regarding their knowledge and behavior toward hydration, almost all respondents $(96 \%)$ considered being well hydrated to be very important, and $57 \%$ affirmed that they try to keep track of how much water they drink. However, $70 \%$ of respondents indicated that they drink less than $2 \mathrm{~L}$ of water per day, and $30 \%$ stated that they currently use a tool to track how much water they drink.

\section{Understanding, Appreciation, and Preference among the 3 Tools}

To define the most relevant design for this tool, we compared the understanding and liking across the singletool evaluations and the preferences obtained from a comparison of the 3 options.

\section{Spontaneous Understanding}

Tool 2 achieved high understanding with $88 \%$ of respondents totally or partially understanding the tool (with $40 \%$ total understanding). Tool 1 achieved $69 \%$ understanding (with $27 \%$ total understanding) and Tool 3 was understood by $73 \%$ of respondents (with $17 \%$ total understanding). Understanding of Tool 2 was significantly higher than understanding of Tool $1\left(\chi^{2}[1, n=\right.$ $845]=43.64, p<0.0001)$ and Tool $3\left(\chi^{2}[1, n=835]=\right.$ $29.12, p<0.0001)$. There was no significant difference of understanding between Tool 1 and Tool $3\left(\chi^{2}[1, n=\right.$ $870]=1.63, p<0.2)$. 
Table 1. Questions and measures in the questionnaire

\begin{tabular}{|c|c|c|}
\hline Topics & Variables & Response modalities \\
\hline $\begin{array}{l}\text { Hydration importance, } \\
\text { hydration-related knowledge, } \\
\text { and behaviors }\end{array}$ & $\begin{array}{l}\text { How important is it for you to drink enough water and keep hydrated? } \\
\text { (To avoid biases, this question was asked at the beginning of the } \\
\text { questionnaire, followed by statements on other healthy habits.) } \\
\text { How much water do you drink every day? } \\
\text { Knowledge of official local AI for total water intake? } \\
\text { How much water should pregnant and breastfeeding women drink? } \\
\text { Would you say that you drink enough water per day? } \\
\text { I am not sure I drink enough water every day. I usually try to keep a } \\
\text { track of how much water I drink during the day. I already use a tool } \\
\text { to track the quantity of water I drink. }\end{array}$ & $\begin{array}{l}\text { Five-point Likert-scale from } \\
\text { "not very important" to } \\
\text { "very important" } \\
\text { Open } \\
\text { Yes/no } \\
\text { Open } \\
\text { Yes/no } \\
\text { Five-point Likert-scale from } \\
\text { "1 = totally disagree" to } \\
\text { "5 = totally agree" }\end{array}$ \\
\hline Spontaneous appreciation & Spontaneous liking: based on your first reaction, do you like this tool? & $\begin{array}{l}\text { Ten-point Likert-scale, } \\
\text { " } 1=\text { I don't like it all" to } \\
\text { " } 10=\text { I like it a lot" }\end{array}$ \\
\hline $\begin{array}{l}\text { Simplicity and relevance of the } \\
\text { tool (after explanation) }\end{array}$ & $\begin{array}{l}\text { This tool ... } \\
\text { Is easy to understand. } \\
\text { Is easy to use. } \\
\text { Is confusing. } \\
\text { Meets my needs to track how much water I drink. } \\
\text { Boosts my motivation to drink (more) water. } \\
\text { Should be presented with other material on hydration. }\end{array}$ & $\begin{array}{l}\text { Five-point Likert-scale, } \\
" 1=\text { not at all" to } \\
\text { " } 5=\text { completely" }\end{array}$ \\
\hline $\begin{array}{l}\text { Appreciation of the tool } \\
\text { (after explanation) }\end{array}$ & Do you like this tool? & $\begin{array}{l}\text { Ten-point Likert-scale } \\
\text { from " } 1=\text { I do not like it all” } \\
\text { to " } 10=\text { I like it a lot" }\end{array}$ \\
\hline Usage intention & Would you use the tool? & $\begin{array}{l}\text { Five-point Likert-scale } \\
\text { from " } 1=\text { certainly not" } \\
\text { to " } 5=\text { certainly yes" }\end{array}$ \\
\hline Socio demographics & $\begin{array}{l}\text { Profession social-economic class } \\
\text { Age } \\
\text { How many children } \\
\text { Number of weeks pregnant }\end{array}$ & Closed-ended questions \\
\hline
\end{tabular}

\section{Spontaneous Liking}

Tools 1 and 2 were significantly more appreciated than Tool 3 (Tool 1: 8.27 [2.17]; Tool 2: 8.30 [2.18]; Tool 3: 7.78 [2.38]. Tool 3 versus Tool 1: $p=0.001$; Tool 3 versus Tool 2: $p=0.0005)$. Interestingly, after written explanation, liking significantly increased for all 3 options (Tool 1: 9.08 [1.60], $p<0.0001$; Tool 2: 9.00 [1.80], $p<0.0001$; and Tool 3: 8.98 [1.68], $p<0.0001)$ and there were no significant differences across the 3 options $(p \geq$ $0.24)$.
Preference after Explanation and after Showing the 3 Options

Tool 2 was preferred by $51 \%$ of participants, far more than Tool $1(33 \%)$ or Tool $3(16 \%)\left(\chi^{2}[2, n=1,275]=\right.$ $241.43, p<0.0001)$.

Simplicity and Relevance for Daily Use of the UC Scale As Tool 2 was preferred, and evaluated as the tool with the greatest understanding and appreciation, we focused specifically on this version of the design to assess simplic- 
Table 2. Respondents' characteristics: demographics, hydration knowledge, and behaviors

\begin{tabular}{|c|c|c|c|c|c|c|c|c|}
\hline & \multicolumn{2}{|c|}{$\begin{array}{l}\text { Poland } \\
(n=459)\end{array}$} & \multicolumn{2}{|c|}{$\begin{array}{l}\text { Mexico } \\
(n=369)\end{array}$} & \multicolumn{2}{|c|}{$\begin{array}{l}\text { Brazil } \\
(n=447)\end{array}$} & \multicolumn{2}{|c|}{ Total $(n=1,275)$} \\
\hline & $n$ & $(\%)$ & $n$ & (\%) & $n$ & (\%) & $n$ & $(\%)$ \\
\hline \multicolumn{9}{|l|}{ Age, years } \\
\hline $18-24$ & 110 & 24 & 103 & 28 & 105 & 23 & 318 & 25 \\
\hline $25-34$ & 276 & 60 & 200 & 54 & 255 & 57 & 731 & 57 \\
\hline Pregnant & 254 & 55 & 223 & 60 & 256 & 57 & 733 & 57 \\
\hline First pregnancy & 82 & 18 & 35 & 9 & 50 & 11 & 167 & 23 \\
\hline Second or more pregnancy & 172 & 37 & 188 & 51 & 206 & 46 & 566 & 77 \\
\hline Breastfeeding & 205 & 45 & 146 & 40 & 191 & 43 & 542 & 43 \\
\hline Primipara & 105 & 23 & 57 & 15 & 109 & 24 & 271 & 50 \\
\hline Multipara & 100 & 22 & 89 & 24 & 82 & 18 & 271 & 50 \\
\hline Between $1.5 \mathrm{~L}$ and less than $2 \mathrm{~L}$ & 151 & 33 & 101 & 27 & 129 & 29 & 381 & 30 \\
\hline Between $2 \mathrm{~L}$ and less than $2.5 \mathrm{~L}$ & 62 & 14 & 90 & 24 & 93 & 21 & 245 & 19 \\
\hline Between $2.5 \mathrm{~L}$ and less than $3 \mathrm{~L}$ & 22 & 5 & 20 & 5 & 52 & 12 & 94 & 7 \\
\hline $3 \mathrm{~L}$ and more & 9 & 2 & 7 & 2 & 23 & 5 & 39 & 3 \\
\hline \multicolumn{9}{|l|}{$\begin{array}{l}\text { Would you say that you drink enough } \\
\text { water per day? }\end{array}$} \\
\hline Yes & 265 & 58 & 222 & 60 & 262 & 59 & 749 & 59 \\
\hline No & 194 & 42 & 147 & 40 & 185 & 41 & 526 & 41 \\
\hline \multicolumn{9}{|l|}{$\begin{array}{l}\text { How much water should pregnant and } \\
\text { breastfeeding women drink? }\end{array}$} \\
\hline $1-2 \mathrm{~L}$ & 175 & 38 & 144 & 39 & 204 & 46 & 523 & 41 \\
\hline $2.1-4 \mathrm{~L}$ & 263 & 57 & 220 & 60 & 226 & 51 & 709 & 56 \\
\hline $4.1-6 \mathrm{~L}$ & 14 & 3 & 2 & 1 & 38 & 9 & 54 & 4 \\
\hline Top 2 (total agreement/agreement) & 270 & 59 & 150 & 41 & 313 & 70 & 733 & 57 \\
\hline Neutral & 85 & 19 & 85 & 23 & 54 & 12 & 224 & 18 \\
\hline Bottom 2 (disagreement/total disagreement) & 104 & 23 & 134 & 36 & 80 & 18 & 318 & 25 \\
\hline \multicolumn{9}{|l|}{$\begin{array}{l}\text { I already use a tool to track the quantity of } \\
\text { water I drink }\end{array}$} \\
\hline Top 2 (total agreement/agreement) & 109 & 24 & 102 & 28 & 172 & 38 & 383 & 30 \\
\hline Neutral & 72 & 16 & 54 & 15 & 50 & 11 & 176 & 14 \\
\hline Bottom 2 (disagreement/total disagreement) & 278 & 61 & 213 & 58 & 225 & 50 & 716 & 56 \\
\hline
\end{tabular}

\footnotetext{
* Personal estimate.
}

ity and relevance of a tool based on the UC scale. Over the 405 respondents, $82 \%$ considered Tool 2 to be easy to understand; only $16 \%$ regarded it as confusing. Moreover, $83 \%$ declared Tool 2 to be easy to use. In terms of relevance for daily use, $80 \%$ of respondents agreed that Tool
2 met their needs for a tool that tracks hydration. Furthermore, the tool was perceived as a boost of motivation to increase water intake, according to $79 \%$ of pregnant and breastfeeding women. Finally, positive usage intentions were expressed by $83 \%$ of respondents, and $86 \%$ would 
recommend the tool to someone else. Regarding supplemental information, 59\% believed that Tool 2 should be presented with other material about hydration.

\section{Discussion}

This study investigated the understanding, appreciation, simplicity, and relevance for daily use of a tool based on the UC scale as a means for pregnant and breastfeeding women to self-assess their hydration. Our extensive, cross-sectional survey of 1,275 respondents produced 3 key results. First, this research identified a superior design: Tool 2 prompted very high spontaneous understanding $(88 \%=40 \%$ totally $+48 \%$ partially $)$ and achieved better global performance in all 3 countries, according to the questionnaire items pertaining to general preferences across the 3 designs. Second, our sample of women reported that being well hydrated is very important, yet the vast majority of participants acknowledged that they drink less than 2 L of water per day, and less than a third of the respondents actually use a tool to measure how much they drink. These observations suggest that Tool 2 could raise awareness about hydration and encourage self-assessment of hydration among pregnant and breastfeeding women. Third, a vast majority of respondents reported that Tool 2 would encourage them to track how much water they drank, and motivated them to drink; they also expressed clear intentions to use this tool.

Though the fluid intake data collected in this study are declarative, they are consistent with surveys that have shown that pregnant and breastfeeding women across the world do not meet the daily AWI $[4,16]$. The overall positive reactions of women in our study, in regards to the simplicity and utility of Tool 2, suggest that a UC scale-based tool could be utilized by healthcare professionals to help pregnant and breastfeeding women selfassess their hydration. In addition to the relevance perceived by the target population, Tool 2 revealed several strengths. First, it was clearly understood, without further instructions, even though it contained only images and illustrations. Second, understanding was not impacted by the spoken language of the user as confirmed among pregnant and breastfeeding women from 3 countries in our study. Third, the tool was greatly appreciated. Given the favorable reactions of participants toward Tool 2, we propose that this tool has the potential to be widely used. These strengths are also relevant to the wellknown gap between science and practice [18]. Despite international dietary guidelines and advice to increase water intake during pregnancy and breastfeeding $[1,2]$, tracking daily total fluid consumption is time consuming. In contrast, Tool 2 accounts for inter-individual differences of water needs due to climate, physical activity, or other factors and provides women with a simple means to evaluate their hydration throughout the day [14]. Translating the validated UC scale to a user-friendly tool represents a key step in bridging the gap between science and practice, and making personalized self-assessment of hydration accessible.

The authors acknowledge 2 limitations of this study. First, respondents did not physically handle the tool (i.e., participants saw an image of the tool on their computer screens), and were exposed to the tool only while they answered the online questionnaire. Further research should conduct extended evaluations across several days and during daily activities. Second, this study was conducted in 2 continents. Although respondents in 3 countries, and speaking 3 languages evaluated Tool 2, future feedback from similar populations in other countries will assess the global utility of the tool. Nonetheless, a positive observation was that respondents in all 3 countries demonstrated a clear understanding of Tool 2. Relevant to this point, a study assessing an illustrated UC-based tool for children (i.e., containing only images with no words) was evaluated in Indonesia, Mexico, and France; the high level of understanding was unrelated to the spoken language [19].

\section{Conclusions}

This study presents a comprehensive evaluation of an illustrated tool based on the UC scale as a means to help pregnant and breastfeeding women self-monitor hydration and adjust water intake if needed. Tool 2 offers a relevant option for pregnant and breastfeeding women, in that it is simple and useful, clearly understood, and highly appreciated. Tool 2 increased the awareness and curiosity of women about hydration and motivated them to increase their water intake according to advised AWI. Therefore, we recommend that future studies evaluate behavioral interventions in real-life settings to measure the impact of tools based on the UC scale.

\section{Ethics Approval and Consent to Participate}

Human Subjects Research that is covered by the regulations Exempt from IRB review_under 45 CFR 46.101(b).
Rigaud/Sevalho Corçao/Perrier/ Boesen-Mariani 


\section{Availability of Data and Materials}

The data supporting the conclusions of this work are available from the corresponding author upon reasonable request.

Tool 2 is available on the hydration for health initiative website: http://www.h4hinitiative.com/.

\section{Disclosure Statement}

S.B.-M. declares being a full-time employee of Danone Nutricia Research. E.T.P. and M.R. declare being full-time employees of Danone Research. C.S.C. was a full-time employee of Danone Research at the time of the study.

\section{Funding}

The research was funded by Danone Research, Palaiseau, France.

\section{Authors' Contributions}

S.B.M. and C.S.C. contributed to the conception and design of the study, performed data analysis, and drafted the manuscript. M.R. and E.T.P. formulated the research questions, contributed to the conception of the study, and drafted the manuscript. All authors read and approved the final manuscript.

\section{Acknowledgments}

We thank Com' des Enfants, the communication agency that designed all the visuals of the tools, and Metrixlab, the market research agency that initiated the recruitment and field organization activities. We also thank Prof. Lawrence Armstrong for his editorial review of this manuscript and for providing access to the UC scale.

\section{References}

1 Institute of Medicine (US) and National Research Council (US) Committee to Reexamine IoM Pregnancy Weight Guidelines: Weight gain during pregnancy: reexamining the guidelines; in Rasmussen KM, Yaktine AL (eds): The National Academies Collection: Reports funded by National Institutes of Health. Washington, National Academies Press (US) National Academy of Sciences, 2009.

2 EFSA Panel on Dietetic Products, Nutrition, and Allergies (NDA): Scientific opinion on dietary reference values for water. EFSA J 2010;8:1459.

3 Neville MC, Keller R, Seacat J, Lutes V, Neifert $\mathrm{M}$, Casey $\mathrm{C}$, et al: Studies in human lactation: milk volumes in lactating women during the onset of lactation and full lactation. Am J Clin Nutr 1988;48:1375-1386.

4 Martinez H: Fluid consumption by Mexican women during pregnancy and first semester of lactation. Biomed Res Int 2014;2014: 603282.

5 Bardosono S, Prasmusinto D, Hadiati DR, Purwaka BT, Morin C, Pohan R, et al: Fluid intake of pregnant and breastfeeding women in Indonesia: a cross-sectional survey with a seven-day fluid specific record. Nutrients 2016;8:pii:E651.

6 McKenzie AL, Perrier ET, Guelinckx I, Kavouras SA, Aerni G, Lee EC, et al: Relationships between hydration biomarkers and total fluid intake in pregnant and lactating women. Eur J Nutr 2016, Epub ahead of print.
7 Perrier E, Demazières A, Girard N, Pross N, Osbild D, Metzger D, et al: Circadian variation and responsiveness of hydration biomarkers to changes in daily water intake. Eur J Appl Physiol 2013;113:2143-2151.

8 Armstrong LE, Maresh CM, Castellani JW, Bergeron MF, Kenefick RW, LaGasse KE, et al: Urinary indices of hydration status. Int J Sport Nutr 1994;4:265-279.

9 Armstrong LE, Soto JA, Hacker FT Jr, Casa DJ, Kavouras SA, Maresh CM: Urinary indices during dehydration, exercise, and rehydration. Int J Sport Nutr 1998;8:345-355.

10 Perrier E, Vergne S, Klein A, Poupin M, Rondeau P, Le Bellego L, et al: Hydration biomarkers in free-living adults with different levels of habitual fluid consumption. Br J Nutr 2013;109:1678-1687.

11 Kavouras SA, Johnson EC, Bougatsas D, Arnaoutis G, Panagiotakos DB, Perrier E, et al: Validation of a urine color scale for assessment of urine osmolality in healthy children. Eur J Nutr 2016;55:907-915.

12 Armstrong LE, Pumerantz AC, Fiala KA, Roti MW, Kavouras SA, Casa DJ, et al: Human hydration indices: acute and longitudinal reference values. Int J Sport Nutr Exerc Metab 2010;20:145-153.
13 Armstrong LE, Johnson EC, Munoz CX, Swokla B, Le Bellego L, Jimenez L, et al: Hydration biomarkers and dietary fluid consumption of women. J Acad Nutr Diet 2012; 112:1056-1061.

14 McKenzie AL, Muñoz CX, Ellis LA, Perrier ET, Guelinckx I, Klein A, et al: Urine color as an indicator of urine concentration in pregnant and lactating women. Eur J Nutr 2017; 56:355-362.

15 Kavouras SA, Arnaoutis G, Makrillos M, Garagouni $\mathrm{C}$, Nikolaou E, Chira O, et al: Educational intervention on water intake improves hydration status and enhances exercise performance in athletic youth. Scand J Med Sci Sports 2012;22:684-689.

16 Bardosono S, Prasmusinto D, Hadiati DR, Purwaka BT, Morin C, Pohan R, et al: Fluid intake of pregnant and breastfeeding women in Indonesia: a cross-sectional survey with a seven-day fluid specific record. Nutrients 2016;8:pii:E651.

17 Campbell I: Chi-squared and Fisher-Irwin tests of two-by-two tables with small sample recommendations. Stat Med 2007;26:36613675.

18 Sexton TL, Hanes CW, Kinser JC: Translating science into clinical practice; in Thomas JC, Hersen M (eds): Handbook of Clinical Psychology Competencies. New York, Springer, 2010, pp 153-180.

19 Guelinckx I, Frémont-Marquis AS, Eon E, Kavouras SA, Armstrong LE: Assessing hydration in children: from science to practice. Ann Nutr Metab 2015;66(suppl 3):5-9. 